\title{
Rozległy ropień zaotrzewnowy u pacjenta z chorobą Leśniowskiego-Crohna penetrujący do stawu biodrowego. Opis przypadku
}

\author{
Extensive retroperitoneal abscess in a patient with Crohn's disease penetrating to the hip \\ joint. A case report
}

\author{
Andrzej Żyluk ${ }^{\bowtie}$, Piotr Puchalski, Zbigniew Szlosser \\ Pomorski Uniwersytet Medyczny w Szczecinie, Klinika Chirurgii Ogólnej i Chirurgii Ręki, ul. Unii Lubelskiej 1, 71-252 Szczecin \\ azyluk@hotmail.com
}

\begin{abstract}
Introduction: Retroperitoneal abscesses are a relatively uncommon complication of diseases of various abdominal viscera, e.g. acute retrocoecal appendicitis or Crohn's disease.

Case report: The paper reports the case of a 37-year-old patient suffering from Crohn's disease, in whom an abscess developed in the right retroperitoneal space, causing compression on the right ureter and penetrating into the right hip joint. The patient was admitted to hospital in a serious clinical state, with impending sepsis. The diagnosis was made based on abdominal computed tomography. The patient was immediately operated on, and the operation consisted in the resection of the involved part of the jejunum and caecum, followed by the evacuation
\end{abstract}

\begin{abstract}
ABSTRAKT
Wstęp: Ropnie przestrzeni zaotrzewnowej stanowią stosunkowo rzadkie powikłanie schorzeń różnych narządów jamy brzusznej, m.in. ostrego zapalenia wyrostka robaczkowego, szczególnie położonego zakątniczo, i choroby Leśniowskiego-Crohna. Opis przypadku: W pracy przedstawiono przypadek 37-letniego pacjenta chorującego na chorobę Leśniowskiego-Crohna, u którego rozwinął się rozległy ropień w prawej przestrzeni zaotrzewnowej, wywołał ucisk na prawy moczowód i przebił się do prawego stawu biodrowego. Pacjent zgłosił się do szpitala będąc w ciężkim stanie ogólnym, z rozpoczynającą się posocznica. Rozpoznanie ustalono na podstawie tomografii komputerowej jamy brzusznej. Pacjent był operowany w trybie pilnym,
\end{abstract}

and drainage of the abscess. Post-operative course was complicated by the occurrence of a mixed, partially mechanical and paralytic obstruction, and anastomotic leakage. At the second operation, a loop jejunostomy was performed, resulting in the stabilization of the abdominal disease. Unfortunately, the hip joint abscess was not evacuated at the right moment, resulting in the joint's destruction, requiring the third (orthopaedic) operation - resection of the femoral head. The patient eventually recovered from abdominal disease complication, but was severely injured and will need a hip joint alloplasty.

Keywords: retroperitoneal abscess; Crohn's disease; complications; hip joint abscess. a leczenie polegało na resekcji części zmienionego jelita czczego i kątnicy, ewakuacji i drenażu ropnia zaotrzewnowego. Przebieg pooperacyjny był powikłany wystąpieniem niedrożności o charakterze mechaniczno-porażennym i nieszczelnością zespolenia jelit. W czasie drugiej operacji wyłoniono jejunostomię pętlową, co przyniosło poprawę stanu i opanowanie choroby brzusznej. Niestety, nieewakuowany w porę ropień stawu biodrowego spowodował jego zniszczenie, co wymagało trzeciej operacji (ortopedycznej) - wycięcia głowy kości udowej. Ostatecznie pacjent wyzdrowiał z powikłania, ale został okaleczony i będzie wymagał alloplastyki stawu biodrowego.

Słowa kluczowe: ropień zaotrzewnowy; choroba LeśniowskiegoCrohna; powikłania; ropień stawu biodrowego.

\section{WSTĘP}

Ropnie przestrzeni zaotrzewnowej są stosunkowo rzadkim powikłaniem schorzeń różnych narządów jamy brzusznej. W porównaniu z ropniami wewnątrzotrzewnowymi, których przyczyną są zwykle zapalenia narządów wewnątrzbrzusznych lub powikłania pooperacyjne, powody ropni zaotrzewnowych są bardziej urozmaicone. Mogą być powikłaniami następujących chorób lub interwencji:

- perforacji przewodu pokarmowego do przestrzeni zaotrzewnowej: owrzodzenia trawiennego, uchyłka dwunastnicy, zapalnie zmienionego wyrostka robaczkowego, uchyłka okrężnicy lub raka okrężnicy [1, 2, 3],

- jatrogennej, zaotrzewnowej perforacji dwunastnicy, np. w czasie wykonywania sfinkterotomii [4, 5],

- zapalenia narządów położonych zaotrzewnowo odmiedniczkowego zapalenia nerek i ostrego zapalenia trzustki,

- pourazowych krwiaków zaotrzewnowych powstałych wskutek złamania kręgosłupa lędźwiowego i kości miednicy,

- choroby Leśniowskiego-Crohna, ropnego zapalenia lub gruźlicy kręgosłupa lędźwiowego [6, 7], 
- w przebiegu bakteryjnego zapalenia wsierdzia jako ropnie przerzutowe drogą krwionośną.

W zależności od przyczyny ropień może znajdować się w górnej (pochodzenia trzustkowego i dwunastniczego) lub w dolnej (pochodzenia okrężniczego, wyrostkowego, urazowego) części tułowia. Ze względu na brak barier anatomicznych cechą charakterystyczną tych ropni jest skłonność do szerzenia się w luźnej tkance łącznej, co sprzyja osiąganiu znacznych rozmiarów i nadaje im charakter ropowicy. Z tego też powodu mogą szybko powodować posocznice, szczególnie u osób w podeszłym wieku, chorych na cukrzycę i z osłabioną odpornością. Mogą też przebijać się do innych struktur, np. do jamy otrzewnowej, stawu biodrowego lub tworzyć przetoki, gdy przebiją się na zewnątrz tułowia.

W pracy przedstawiono przypadek pacjenta z długoletnią chorobą Leśniowskiego-Crohna, u którego rozwinął się rozległy ropień w prawej przestrzeni zaotrzewnowej, a następnie przebił się do prawego stawu biodrowego. Leczenie rozpoczęto późno, w fazie znacznego zaawansowania choroby, i choć zakończyło się pomyślnie, to jednak było powikłane zniszczeniem stawu biodrowego.

\section{SPOSTRZEŻENIE WŁASNE}

37-letni pacjent został przywieziony ambulansem pogotowia ratunkowego na Szpitalny Oddział Ratunkowy Samodzielnego Publicznego Szpitala Klinicznego nr 1 w Szczecinie z lotniska w Goleniowie z powodu bólu brzucha, gorączki i znacznego osłabienia. Pacjent przyleciał do Szczecina rejsem z Londynu. Z wywiadu uzyskano następujące informacje:

1. Pacjent od 11 lat leczy się z powodu choroby Leśniowskiego-Crohna.

2. Od ok. 4 tygodni występowały typowe objawy zaostrzenia: ból brzucha, utrata apetytu, biegunka (kilka luźnych stolców na dobę) i gorączka $\left(38-39^{\circ} \mathrm{C}\right)$, czemu towarzyszyło znaczne osłabienie.

3. Od ok. tygodnia występował ból w okolicy prawego stawu biodrowego, uniemożliwiający chodzenie.

4. W czasie pobytu w Anglii pacjent zgłaszał się do lekarza pierwszego kontaktu, który przepisywał mu doustne steroidy. Pomimo braku poprawy pacjent nie został skierowany do szpitala.

Badaniem przedmiotowym stwierdzono:

1. Pacjent leżący, w stanie ogólnym średnio ciężkim, wychudzony i gorączkujący $\left(39^{\circ} \mathrm{C}\right)$.

2. Brzuch napięty, lekko wzdęty, bolesny przy badaniu na całej powierzchni, ale najbardziej w prawym dole biodrowym, z zaznaczonymi w tej okolicy objawami otrzewnowymi.

3. Osłuchiwaniem brzucha - perystaltyka słyszalna, wzmożona.

4. Ograniczenie ruchomości prawego stawu biodrowego z powodu bólu, który powodował każdy ruch kończyną.

Badania biochemiczne wykazały podwyższone parametry stanu zapalnego: liczba leukocytów - 16 G/L, stężenie białka C-reaktywnego - $370 \mathrm{mg} / \mathrm{L}$ i stężenie prokalcytoniny - $6 \mathrm{ug} / \mathrm{dL}$, co świadczyło o rozpoczynającej się posocznicy.
Badanie tomografii komputerowej (TK) jamy brzusznej z kontrastem wykazało:

1. Rozległy ropień przestrzeni zaotrzewnowej po stronie prawej, układający się wzdłuż prawego talerza biodrowego w mięśniu biodrowo-lędźwiowym, otaczający prawy staw biodrowy z obu stron i schodzący na przednią powierzchnie prawego uda (ryc. 1 i 2).

2. Drugi ropień przestrzeni zaotrzewnowej w miednicy małej, otaczający prawy staw biodrowy od strony przyśrodkowej.

3. Naciek zapalny końcowego odcinka jelita cienkiego z ropniem i oklejoną perforacją.

4. Lity naciek zapalny prawego moczowodu w miednicy małej, z poszerzeniem bliższego odcinka moczowodu do $1 \mathrm{~cm}$ i średniego stopnia wodonerczem prawostronnym (ryc. 2).

Wobec takiego obrazu klinicznego i radiologicznego, pacjenta przyjęto na oddział chirurgiczny i zdecydowano o wykonaniu pilnej laparotomii.

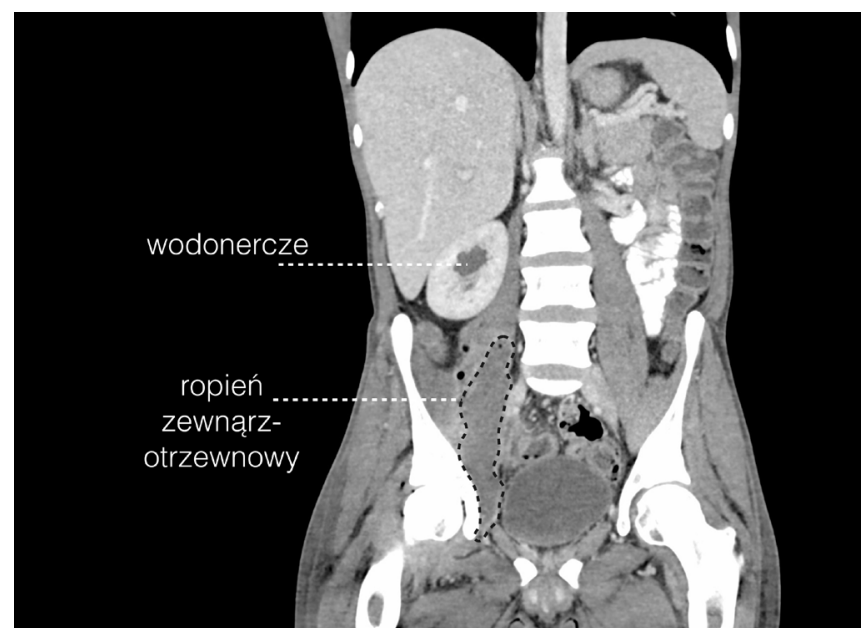

RYCINA 1. Obraz tomografii komputerowej jamy brzusznej z ropniem zaotrzewnowym po stronie prawej

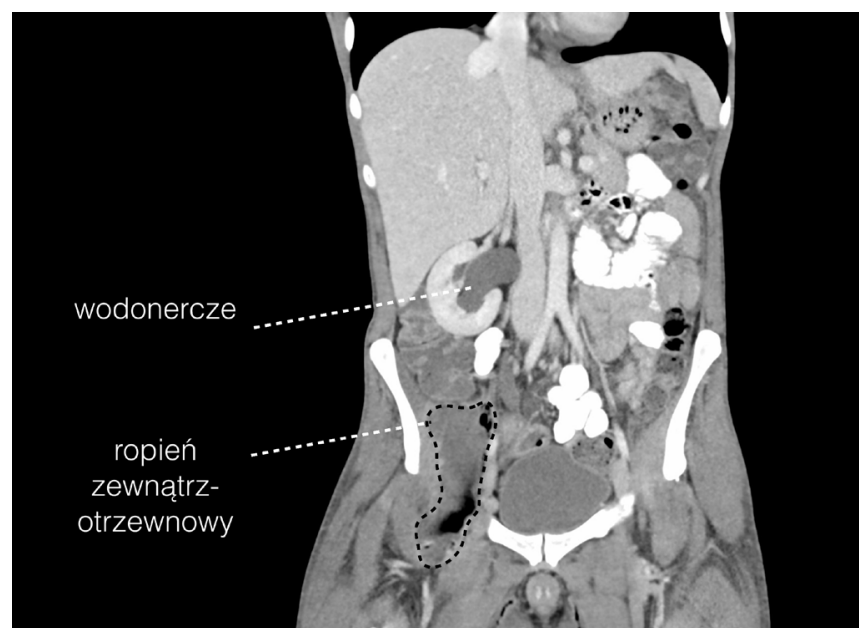

RYCINA 2. Obraz tomografii komputerowej jamy brzusznej z ropniem zaotrzewnowym po stronie prawej i prawostronnym wodonerczem 


\section{SPOSTRZEŻENIA ŚRÓDOPERACYJNE (1 OPERACJA)}

Jamę otrzewnową otwarto z cięcia pośrodkowego w podbrzuszu przechodzącego do połowy nadbrzusza. Po otwarciu otrzewnej ewakuowano umiarkowaną objętość mętnego płynu, który pobrano do badania bakteriologicznego. Pętle jelita krętego były w zrostach zapalnych i miały na surowicówce naloty włóknikowe. Ostrożnie uwolniono jelito końcowe, stwierdzając jego pogrubienie i wzmożoną spoistość, niewielką, oklejoną perforację, a także ropień w okolicy nacieczonej kątnicy. Nacięto otrzewną po bocznej stronie kątnicy i otwarto przestrzeń zaotrzewnową, skąd ewakuowano ok. $600 \mathrm{~mL}$ gęstej ropy. Tak jak wskazywał obraz TK, ropień przechodził na prawy staw biodrowy, otaczał prawe naczynia biodrowe i po powierzchni mięśnia biodrowo-lędźwiowego schodził na przednią powierzchnię uda. Ropień ewakuowano, wykonano płukanie środkiem antyseptycznym i założono do środka dren, który wyprowadzono przez nacięcie na przedniej stronie prawego uda. W miednicy małej wykonano nacięcie otrzewnej ściennej i otwarto drugi ropień przestrzeni zaotrzewnowej, który także ewakuowano i zdrenowano. Ze względu na znaczne zmiany zapalne końcowego odcinka krętego i kątnicy oraz perforację jelita zdecydowano się je resekować i zespolić bok do boku jelito kręte z wstępnicą. Kikuty jelit zamknięto szwem mechanicznym. Jamę otrzewnową i jamy po ropniach zaotrzewnowych wypłukano, założono 3 dreny i zamknięto brzuch warstwowo.

\section{PRZEBIEG POOPERACYJNY}

Po operacji wdrożono antybiotykoterapię (ceftriakson $2 \times 1,0 \mathrm{~g}$ i metronidazol $3 \times 0,5 \mathrm{~g}$ ), profilaktykę przeciwzakrzepową i podawano dożylnie płyny. Z drenów ewakuowało się ok. 600-800 mL treści surowiczo-krwistej na dobę. Od 3. doby pooperacyjnej rozpoczęto pojenie; w 4. dobie ze względu na anemizację przetoczono 2 jednostki koncentratu krwinek czerwonych. Wynik badania bakteriologicznego materiału pobranego w czasie operacji wykazał obecność bakterii E. coli, Streptococcus anginosus i Prevotella bivia, które były wrażliwe na zastosowane antybiotyki. Nie obserwowano zaburzeń pracy prawej nerki. Od 5. doby stan pacjenta zaczął się pogarszać, pojawił się ból, wzdęcie brzucha i wymioty treścią zalegającą, co sugerowało niedrożność mechaniczną jelita cienkiego. Z założonej do żołądka sondy ewakuowało się w ciągu doby ok. 1000 mL treści. Ponieważ leczenie objawowe nie przynosiło poprawy, wykonano TK jamy brzusznej, która wykazała zaleganie kontrastu w końcowym odcinku jelita krętego, z niewielkim tylko przejściem poza zespolenie do wstępnicy, co wskazywało na niedrożność mechaniczną z zatkania. Badanie TK ujawniło także ropień w okolicy zespolenia i ustąpienie prawostronnego wodonercza. Przy takim obrazie klinicznym i radiologicznym w 8. dobie po pierwszej operacji wykonano relaparotmię.

\section{SPOSTRZEŻENIA ŚRÓDOPERACYJNE (2 OPERACJA)}

Po otwarciu jamy brzusznej przez ranę po pierwszej operacji stwierdzono niedrożność mechaniczną końcowego odcinka jelita krętego spowodowaną zatkaniem przez wypełniającą jelito gęstą treść (ryc. 3). Wyglądało to tak, jakby perystaltyka jelita była za słaba, aby przepchnąć gęstą treść do jelita grubego, co powodowało niedrożność. Odnaleziono zespolenie jelita krętego z wstępnicą i stwierdzono nieszczelność kikuta jelita cienkiego zszytego szwem mechanicznym. Samo zespolenie było wydolne i szczelne. Ewakuowano ropień powstały w okolicy zespolenia. Mając taki obraz śródoperacyjny, zdecydowano o wykonaniu ileostomii odbarczającej ok. $50 \mathrm{~cm}$ od zespolenia. Nacięto jelito kręte, ewakuowano ok. 800 mL gęstej, zalegającej treści i wyłoniono ileostomię pętlową (ryc. 4). Zszyto nieszczelny kikut jelita przy zespoleniu. Pobrano materiał

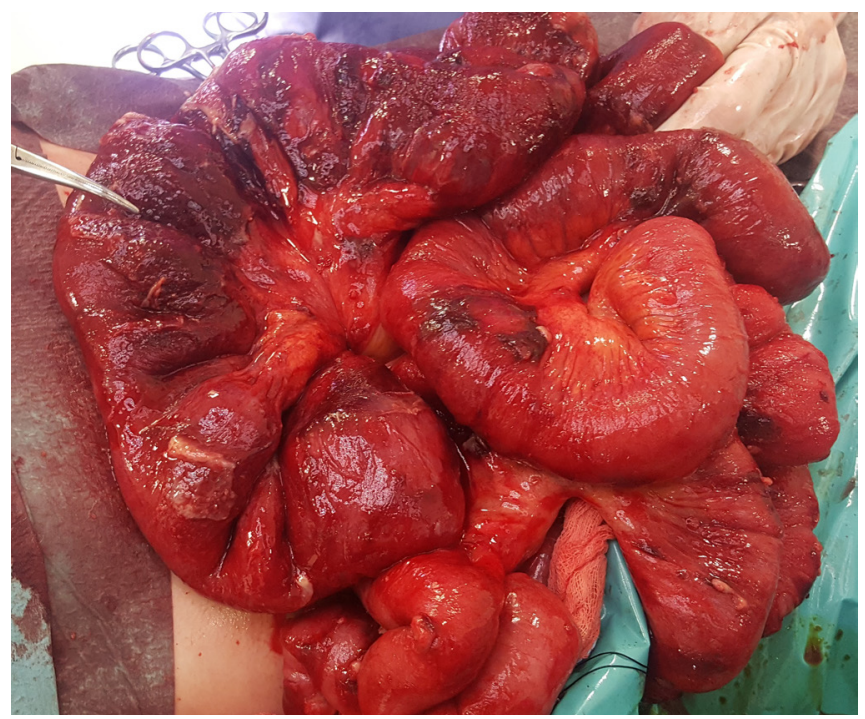

RYCINA 3. Widok śródoperacyjny zmienionego jelita cienkiego przy drugiej operacji brzusznej

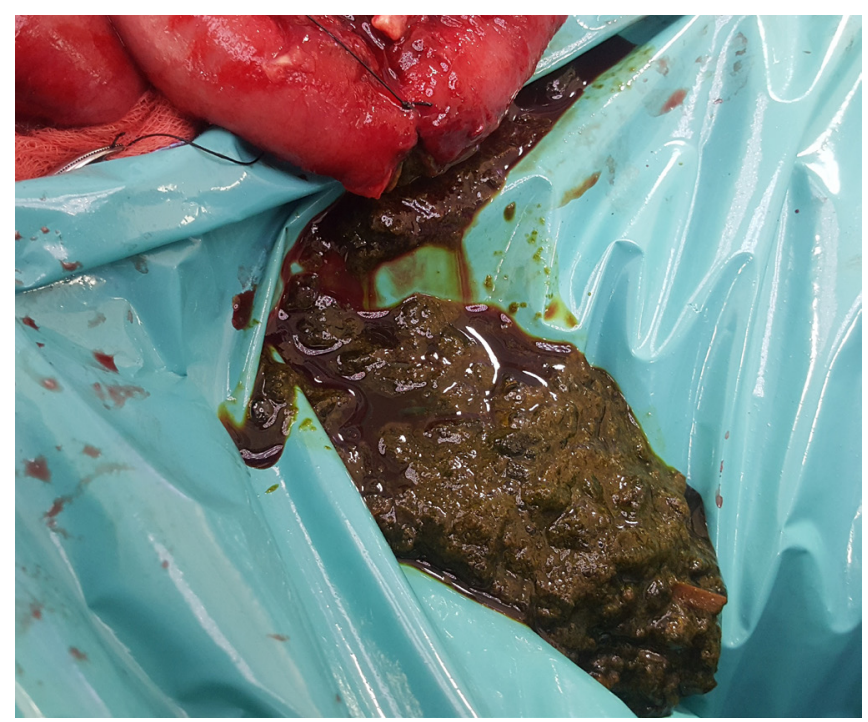

RYCINA 4. Gęsta treść jelitowa zatykająca jelito cienkie i powodująca niedrożność 
do badania bakteriologicznego, wypłukano jamę otrzewnową, założono dreny i zamknięto brzuch.

\section{PRZEBIEG POOPERACYJNY (2)}

Po drugiej operacji dość długo utrzymywała się gorączka $37-38^{\circ} \mathrm{C}$. Kontynuowano celowaną antybiotykoterapię przeciwko paciorkowcowi Streptococcus anginosus wyhodowanemu z materiału pobranego przy drugiej operacji. Pogłębiło się niedożywienie pacjenta, który w ciągu 2 tygodni od przyjęcia do kliniki stracił ok. 10 kg i ważył 48 kg przy 184 cm wzrostu. Ileostomia funkcjonowała dobrze i od 3. doby rozpoczęto odżywianie doustne. Wdrożono też uzupełniające żywienie pozajelitowe. Usunięto dreny z jamy otrzewnowej, pozostawiając jeden wyprowadzony na prawym udzie, który drenował okolicę stawu biodrowego i z którego ewakuowało się ok. 100-150 mL mętnej treści na dobę.

Stan pacjenta zaczął się powoli stabilizować i po tygodniu od drugiej operacji rozpoczęto jego uruchamianie. Przebiegało ono z dużymi problemami ze względu na silny ból prawego stawu biodrowego, uniemożliwiający obciążenie kończyny. Wykonano RTG prawego stawu biodrowego, które wykazało znacznie nasilone zmiany zapalne i zwyrodnieniowe, a także USG, które uwidoczniło gęsty płyn w stawie odsuwający torebkę stawową na ok. $1 \mathrm{~cm}$. Poproszono na konsultację ortopedę, który zalecił postępowanie zachowawcze i antybiotykoterapię aż do zakończenia leczenia zakażenia brzusznego. W dalszym ciągu hospitalizacji stan pacjenta poprawił się, ustąpiła gorączka, wrócił mu apetyt, ileostomia funkcjonowała dobrze, a rana operacyjna zagoiła się. Udało się go także uruchomić tak, że poruszał się za pomocą balkonika lub w asyście innej osoby. Obciążanie prawej kończyny dolnej powodowało jednak nadal znaczny ból. Po równo miesiącu od przyjęcia pacjenta na jego własną prośbę (konieczność uregulowania formalności po przerwanej pracy w Anglii) wypisany został na krótko do domu.

\section{DRUGI POBYT W SZPITALU}

Po 10 dniach pacjenta przyjęto ponownie na oddział i wykonano TK prawego stawu biodrowego, które wykazało obecność ropnia, znaczną destrukcję elementów kostnych stawu i podwichnięcie głowy kości udowej (ryc. 5 i 6). Po konsultacji pacjenta przekazano do kliniki ortopedii, gdzie po krótkim przygotowaniu wykonano operację: resekcję głowy kości udowej, wszczepienie preparatu Stimulan (substytut kostny do leczenia miejscowego zakażeń kości i tkanek miękkich wypełniający martwą przestrzeń po resekcji zakażonej tkanki. Można do niego dodawać większość antybiotyków, które są powoli uwalniane do sąsiadujących tkanek) i drenaż stawu biodrowego. Przebieg pooperacyjny był powikłany zakażeniem i przedłużonym gojeniem się rany operacyjnej, która ostatecznie zagoiła się po miesiącu. Zagoiła się także przetoka na udzie, po drenażu ropnia przy pierwszej operacji. Pacjent poruszał

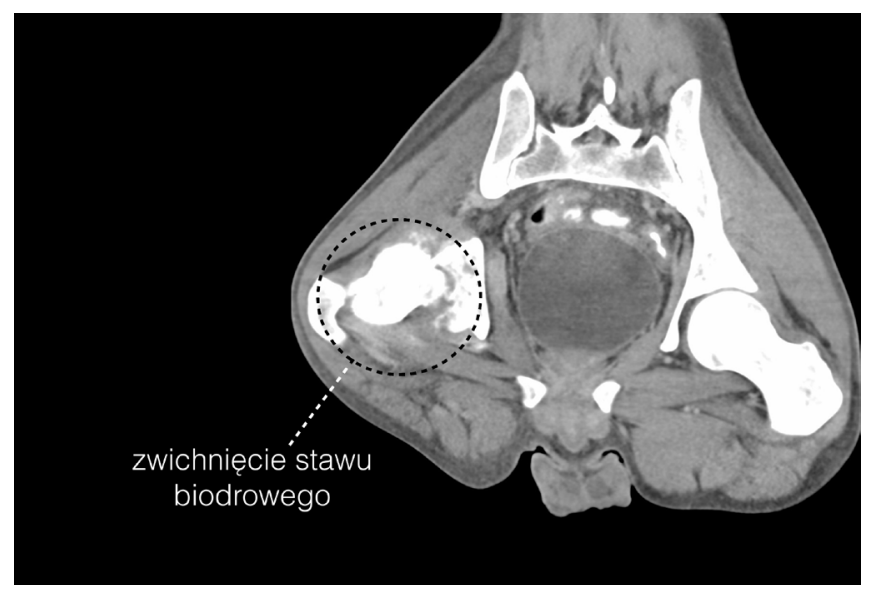

RYCINA 5. Obraz tomografii komputerowej podwichnięcia i destrukcji prawego stawu biodrowego

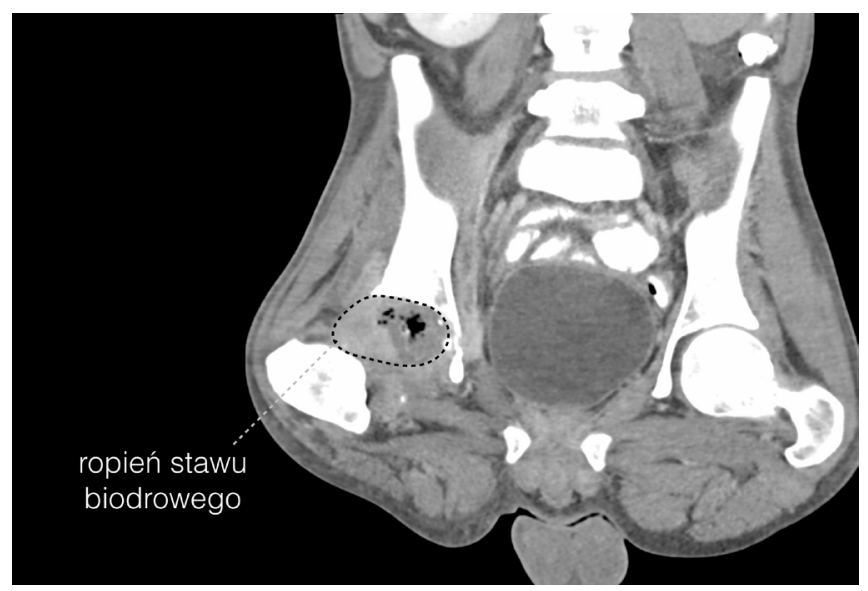

RYCINA 6. Obraz tomografii komputerowej ropnia prawego stawu biodrowego

się na wózku i rozpoczęto próby jego pionizacji. Po 6 tygodniach został wypisany do domu, mając zaplanowany kolejną hospitalizację na oddziale chirurgicznym w celu likwidacji ileostomii, a potem na oddziale ortopedii do wykonania alloplastyki stawu biodrowego.

\section{OMÓWIENIE}

Opisany przypadek jest ciekawy z kilku powodów:

- rozwinięcie się dużego ropnia zaotrzewnowego jako powikłanie choroby Leśniowskiego-Crohna,

- penetracja ropnia do stawu biodrowego,

- przedłużające się i nieskuteczne leczenie ambulatoryjne prowadzone w Anglii u pacjenta, który bezwzględnie wymagał hospitalizacji.

Tak rozległy ropień zaotrzewnowy, sięgający i przebijający się do stawu biodrowego, jest stosunkowo rzadkim powikłaniem choroby Leśniowskiego-Crohna, tylko raz opisanym w polskim piśmiennictwie [7]. Można mieć pewne zastrzeżenia do postępowania chirurgicznego przy pierwszej operacji, gdyż wydaje się, że bezpieczniejszym rozwiązaniem byłoby wykonanie od razu ileostomii pętlowej zamiast ryzykownego zespolenia w zakażonym środowisku jamy otrzewnowej. To mogłoby 
uchronić pacjenta od drugiej laparotomii. Wydaje się także, że interwencja ortopedyczna była opóźniona, czego konsekwencją było zupełne zniszczenie stawu biodrowego przez nieewakuowany w porę ropień. Trudno stwierdzić, czy staw był do uratowania, gdyby operację przeprowadzono wcześniej, ale z pewnością stworzyłoby to jakąś szansę. Trzecim ciekawym wątkiem jest przebieg leczenia w Wielkiej Brytanii. Wydaje się, że w przebywający w Polsce Brytyjczyk, u którego wystąpiłyby objawy powikłań choroby Leśniowskiego-Crohna, trafiłby do szpitala znacznie wcześniej. Jest to przyczynek do powszechnego utyskiwania na poziom służby zdrowia w naszym kraju, który w wielu przypadkach (szczególnie nagłych) przewyższa standardy zachodnioeuropejskie.

Podobny przypadek przedstawili Milewski i Szczepanek u 19-letniego pacjenta, który w ciągu roku był kilkakrotnie hospitalizowany i 3-krotnie operowany z powodu ropni zaotrzewnowych w obrębie prawego mięśnia biodrowo-lędźwiowego sięgających do talerza biodrowego. Jedna z komór ropnia penetrowała do prawego stawu biodrowego, a druga do spojenia łonowego. Przyczynę powstawania ropni - chorobę Leśniowskiego-Crohna ustalono na podstawie badań obrazowych i histologicznych wyciętego fragmentu jelita cienkiego. Podobnie jak w opisie niniejszego przypadku staw biodrowy został uszkodzony i pacjent wymagał alloplastyki [7].

Mallia i wsp. opisują przypadek ropnia zaotrzewnowego u 88-letniego pacjenta chorującego na cukrzycę, który został przyjęty do szpitala z powodu trwającego miesiąc bólu lewego uda uniemożliwiającego normalne chodzenie (obciążanie lewej kończyny dolnej). Przy przyjęciu pacjent był w stanie septycznym, z objawami zakażenia układu moczowego po stronie lewej, a TK jamy brzusznej i lewego uda ujawniła rozległy ropień zaotrzewnowy sięgający od lewej nerki aż do mięśni lewego uda. Pomimo szybkiego drenażu ropnia i kilkulekowej antybiotykoterapii pacjent zmarł i nie ustalono, co było przyczyną powstania ropnia [8].
W naszej wcześniejszej pracy opisaliśmy przypadek pacjenta, u którego rozległy ropień lewej przestrzeni zaotrzewnowej przebił się do jamy otrzewnowej i przez skórę do przestrzeni międzyżebrowej [9]. Rozpoznanie ustalono na podstawie badania TK jamy brzusznej, a leczenie operacyjne przez laparotomię, ewakuację oraz drenaż ropnia było skuteczne i pacjent wyzdrowiał.

\section{PIŚMIENNICTWO}

1. Fanning DM, Barry M, O’Brien GC, Leahy AL. Perforation of a retrocaecal appendix presenting clinically as a right lumbar abscess. Surgeon 2007;5:368-70

2. Ofrim OI, Legrand MJ. Retroperitoneal abscess resulting from perforated retrocecal appendicitis: a case report. Acta Chir Belg 2013;113(2):149-51.

3. Cacurri A, Cannata G, Trastulli S, Desiderio J, Mangia A, Adamenko O, et al. A rare case of perforated descending colon cancer complicated with a fistula and abscess of left iliopsoas and ipsilateral obturator muscle. Case Rep Surg 2014;2014. doi: 10.1155/2014/128506.

4. Sadatomo A, Koinuma K, Zuiki T, Lefor AT, Yasuda Y. Retroperitoneal abscess associated with a perforated duodenal ulcer. Clin J Gastroenterol 2013;6(5):373-7. doi: 10.1007/s12328-013-0417-7.

5. Żyluk A, Jagielski W. Ostre zapalenie trzustki po endoskopowej ewakuacji kamienia żółciowego przebiegające z objawami przedziurawienia dwunastnicy - opis przypadku. Pomeranian J Life Sci 2015;61(2):176-9. doi: $10.21164 /$ pomjlifesci.75.

6. Veroux M, Angriman I, Rufollo C, Fiamingo P, Caglia P, Madia C, et al. Psoas abscess: a rare complication of Crohn's disease. Acta Chir Belg 2004;104:187-90. doi: 10.1080/00015458.2004.11679533.

7. Milewski A, Szczepanek A. Choroba Leśniowskiego-Crohna u 19-letniego mężczyzny powikłana ropniami zaotrzewnowymi i zapaleniem prawego stawu biodrowego. Wiad Lek 2013;66:244-8.

8. Mallia AJ, Ashwood N, Arealis G, Galanopoulos I. Retroperitoneal abscess: an extra-abdominal manifestation. BMJ Case Rep 2015. doi: 10.1136/ bcr-2014-207437.

9. Żyluk A, Puchalski P, Janowski P. Rozległy ropień lewej przestrzeni zaotrzewnowej o niewyjaśnionej etiologii, przebijający się do jamy otrzewnej - opis przypadku. Pomeranian J Life Sci 2016;62(1):85-8. doi: 10.21164/pomjlifesci.206. 